$\begin{array}{r}\text { Volume and Issues Obtainable at Center for Sustainability Research and Consultancy } \\ \text { Journal of Business and Social Review in Emerging Economies } \\ \text { ISSN: 2519-089X (E): 2519-0326 } \\ \text { Volume 6: No. 4, December 2020 } \\ \text { JSRᄃ } \\ \text { Journal homepage: www.publishing.globalcsrc.org/jbsee } \\ \hline\end{array}$

\title{
Mechanism Between Organizational Support Factors and Motivation to Transfer: Mediating Role of Self-Efficacy
}

\author{
${ }^{1}$ Zeshan Ahmer, ${ }^{2}$ Muhammad Aamir, ${ }^{3}$ Majid Ali, ${ }^{4}$ Muhammad Usman \\ ${ }^{1}$ Assistant Professor, Institute of Business Administration, University of the Punjab, Lahore, Pakistan, \\ zeshan@ibapu.edu.pk \\ ${ }^{2}$ Assistant Professor, Hailey College of Commerce, University of the Punjab, Lahore, Pakistan, \\ aamir@hcc.edu.pk \\ ${ }^{3}$ Assistant Professor, Hailey College of Commerce, University of the Punjab, Lahore, Pakistan, \\ puhailey@gmail.com \\ ${ }^{4}$ Assistant Professor, Hailey College of Commerce, University of the Punjab, Lahore, Pakistan, \\ usmanhc@yahoo.com
}

\begin{tabular}{l}
\hline ARTICLE DETAILS \\
\hline History \\
Revised format: November \\
2020 \\
Available Online: December \\
2020 \\
\hline Keywords \\
self-efficacy, motivation to \\
transfer, perceived supervisor \\
support, perceived \\
organizational support.
\end{tabular}

JEL Classification

MO, M1

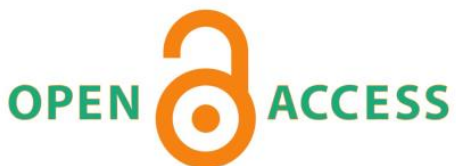

\section{ABSTRACT}

Transfer of training has turned out to be a major issue for the banking industry and the desire of successful transferability of training content can be actualized by motivating the trainees to transfer their learned skills. Therefore, this study highlighted the less studied variables from organizational factors (i.e. organizational and supervisor support) and trainee's characteristics (i.e. self-efficacy) to develop a model for motivation to transfer. For the purpose, data were collected from 388 banking employees and the hypotheses were investigated by means of structural equation modeling using AMOS. The study found both organizational and supervisor support as contributing factors towards motivation to transfer through self-efficacy. The study has implications for the banking sector to cope with this emerging issue.

(C) 2020 Center for Sustainability Research and Consultancy Pakistan under a Creative Commons Attribution-NonCommercial-ShareAlike

4.0

Corresponding author's email address: zeshan@ibapu.edu.pk

Recommended citation: Ahmer, Z., Aamir, M., Ali, M. \& Usman, N. (2020). Mechanism Between Organizational Support Factors and Motivation to Transfer: Mediating Role of Self-Efficacy. Journal of Business and Social Review in Emerging Economies, 6(4), 1621-1630

\section{Introduction}

In today's knowledge-based economy, organizations are striving to gain a competitive advantage over their rivals (Islam \& Ahmed, 2018; Islam et al., 2021; Islam et al., 2020). Studies in the domain of management have suggested establishing a learning culture, designing organizational structure, caring employee's career growth, focusing on HR practices as well as developing employees (Bates \& Khasawneh, 2005; Islam \& Ahmed, 2018; Islam, 2019) to gain competitive advantage. However, Tian et al., (2016) emphasized focusing on 'transfer of training' as it is an essential but neglected aspect of employee's development. It is evident that organizations spend a huge amount on the training of their 
employees but remained unable to get the desired results, because the majority of the trainees are not intended to transfer the acquired skilled (Salas \& Kosarzycki, 2003; Silverman, 2012). Training provided by US Postal Service and Burger King can be considered as the best examples where organizations have to suffer millions of dollars (Bunch, 2007; Feiden, 2003). Further, Salas et al., (2003) argued that "... learning through training programs usually disseminated within a year" in the service sector.

Service sectors contribute 80 percent (in the case of developed countries) and 60 percent (in case of developing countries) in the country's gross domestic products. Amongst many services sectors, the significance of the banking sector cannot be overlooked. In Pakistan, State Bank of Pakistan (SBP) is the regulatory authority for all the conventional and Islamic banks. According to the latest press release, banks in Pakistan lack in providing training programs to its employees, and if so, most of the trainees remained unable to transfer their learned skills at the workplace (Azam, 2016). Given that, the prime focus of this study is on Motivation to Transfer (MTT) as motivated employees can better transform their newly learned knowledge and skills at their workplace (Islam, 2019).

Motivation to transfer training refers to "the learner's intended efforts to utilize skills and knowledge learned in training setting to a real-world work situation (Burke \& Hutchins, 2007, p. 167).” According to Facteau et al., (1995), the presence of motivation is essential for learners because efficacious learners are more likely to perform better to accomplish organizational goals. Despite the fact that MTT is more inspirational construct compared to transfer of training (Burke \& Hutchins, 2007), it was considered rarely by preceding researchers. Literature has highlighted organizational factors and trainee's characteristics as main aspects that contribute in motivation to transfer (Chauhan, Ghosh, Rai, \& Shukla, 2016). Studies on the association between trainee's characteristics with motivation to transfer are well documented, whereas how organizational factors contribute in motivating trainees to transfer their learned knowledge still need to shed light (Islam, 2019; Islam \& Tariq, 2018). However, this study considered both the aspects to understand the mechanism between the same. More specifically, according to Van den Bossche, Segers and Jansen (2010), researchers need to study the association of perceived organizational support (POS) and perceived supervisor support (PSS) with motivation to transfer (MTT) as previous studies are of mixed results. In addition, the association of self-efficacy (from trainee's characteristics) with MTT is well documented (Yamkovenko \& Holton, 2010). However, studies are not well documented about the mediating role of self-efficacy towards MTT.

Organizational Support Theory (OST) provides a base for this study. OST states that employees' with the perception of care and support by their organization, reciprocate with greater or similar values (Rhoades \& Eisenberger, 2002). The receptive work environment in the form of support provided by organization and supervisors may not only develop a sense of being acknowledged and remunerated for remarkable performance, but also enhances self-reliance of individuals (Bandura, 1995), which not only effect on their self-efficacy but also motivate them to apply their learned skills at the workplace. Therefore, this study investigates the effects of perceived organizational support and perceived supervisor support on MTT through self-efficacy.

\section{Hypotheses development}

The concept MTT is important for human resource development. Cheng and Hampson (2008) mentioned that there is a need to explore hidden variables related with the transfer of training because learning in training does not transfer automatically, motivation of trainee for transfer is an unavoidable factor. Literature indicates that work environment and personal emotions are most relevant factors that motivate trainee for transfer of training (Zumrah \& Boyle, 2015). Work-environment related factors include peer support (Martin, 2010), supervisory support (Saks \& Belcourt, 2006), preferred support (Pham, Segers, \& Gijselaers, 2013) and top management support (Kupritz \& Hillsman, 2011). Whereas, personal factors include motivation to transfer (Devos et al., 2007), employees' personality (Yamkovenko \& Holton, 2010) and self-efficacy (Velada et al., 2007). The interaction of some work 
environment factors and personal characteristics such as perceived supervisor support (PSS), POS, selfefficacy, and MTT have been over-sighted by previous studies. The current study indents to investigate such relationships to fill existing void.

Generally, MTT is influenced through organizational support and personal intention of the employee to transfer training at workplaces. The positive attitude of the organization enhances the motivation of employee to transfer back skills which he/she learned during a training session. Training skills cannot be transferred through mechanical ways but it is motivated through organizational and personal emotions of employees (Bosset \& Bourgeois, 2015). The previous literature directs that POS and self-efficacy are quite an influential factor that effects MTT but they have been examined in isolation and structural linkage of these variables is missing in the literature (Chiaburu \& Lindsay, 2008; Chiaburu \& Marinova, 2005). The literature unveiled that POS positively influences employees' attitudes and behavior (Ahmed, Ismail, Amin, \& Islam, 2014; Islam, Khan, Khawaja, \& Ahmad, 2017; Islam \& Tariq, 2018; Rozkwitalska \& Basinska, 2015). Meta-analysis on POS disclosed that it has a direct effect on individual-level outcomes (Ahmed \& Nawaz, 2015; Riggle, Edmondson, \& Hansen, 2009; Rhoades \& Eisenberger, 2002) but prior studies have ignored the impact of POS on subjective aspect of employees' welfare. As Caesens and Stinglhamber (2014) describe that POS improve the subjective behavior of employees through physiological and emotional ways. Self-efficacy is one of the important aspects of the subjective welfare of employees. Therefore, the present study has used self-efficacy as a mediator to explain the relationship between POS and MTT in accordance with many of previous studies conducted in the service sector. Caesens and Stinglhamber (2014) used self-efficacy as a mediator while studying the relationship between POS and work engagement. Islam and Ahmed (2018) also used this variable as a mediator while investigating the association between POS and transfer of training.

POS is one of the organizational factors that influences MTT. Theoretically, POS help employees in a subjective way by satisfying their socio-emotional needs like commitment, affiliation and self-efficacy. Consequently, POS promotes employees' commitment towards job and extra-role performance in the organization (Bosset \& Bourgeois, 2015). Recently, the importance of MTT has increased because it is a vital factor to ensure training transfer. MTT is divided into two dimensions, such as autonomous motivation and controlled motivation. Autonomous motivation is defined as the internal desire of an individual to transfer training whereas, controlled motivation is regulated through organizational rewards and incentives (Gegenfurtner et al., 2009). Previous studies have proposed two factors, namely, self-efficacy and motivation to learn and they are believed to have a significant influence on MTT (Kontoghiorghes, 2002; Machin \& Fogarty, 2004; Paulsen \& Kauffeld, 2017). The above discussion indicates that the influence of POS on MTT seems to be essential for the transfer of training, however, its impacts may be examined. Therefore, it is hypothesized that:

H1: POS has positive impact on MTT.

H2: POS has positive impact on self-efficacy.

H3: Self-efficacy mediates the positive association between POS and MTT.

The relevance of POS with MTT may not be refuted but environmental factors such as supervisory support, co-worker support, managerial support, and learning culture are equally important to motive employees for transfer of training (Islam, Khan, Ahmad, \& Ahmed, 2013; Martin, 2010; Pham et al., 2013). Previous studies (e.g. Ghosh, Chauhan, \& Rai, 2015; Lancaster, Milia, \& Cameron, 2013) revealed divergent results to explain the relationship between PSS and MTT. A group of studies found a strong and position association between PSS and MTT (Cromwell \& Kolb, 2004; Gumuseli \& Ergin, 2002). As Chiaburu and Lindsay (2008) reported a positive influence of PSS on MTT on the individual as well as on group level. Whereas another group of studies found a moderate association between these variables, reported mixed results and suggested that future studies should clarify the relationship between PSS and MTT through further investigation (Burke \& Hutchins, 2007). Some of the studies have proposed that PSS normally influences MTT indirectly, therefore, the relationship of both variables 
should be investigated through any mediator (Bhatti, Battour,Sundram, \& Othman, 2013; Nijman, Nijhof, Wognum, \& Veldkamp, 2006). There is a dearth of literature that predicts the negative and nonsignificant association between PSS and MTT, however, few researchers proclaim that no association exists between these variables (Chiaburu \& Marinova, 2005). According to Baldwin and Ford (1988), work environment factors may be classified into three categories: general-environmental factors, general, and specific training factors. Richey (1992) added that these factors are interrelated with each other, therefore, general-environmental factors impact general-training related factors that consequently impact specific factors related to training. Furthermore, Nijman et al. (2006) suggested three separate components of work environment that influence training transfer: a) general work environment; b) specific work environments that is an intention to transfer training; c) supervisor supportive behavior to enhance transfer. They consider it as a separate and significant component of the work environment. The review of literature witnesses the independent relationship between PSS and MTT and relationship between self-efficacy and MTT, however, a little effort is made to investigate the relationship between PSS and MTT through mediating role of self-efficacy (Simosi, 2012). Self-efficacy is the part of the cognitive process that motivates individuals to enhance their emotional and motivational performance because individuals with high self-efficacy put more effort to achieve high performance. Self-efficacy positively influences transfer intentions and transfer promoting activities.

Though, it is perceived that employees with high self-efficacy are more likely to get innovative skills through training and are not only enthusiastic to newly learned skills on the job but also encourage their colleagues to apply their training at the workplace. Several studies narrate that trainee who is confident about his abilities would be more inclined to apply and transfer training e.g., (Al-Eisa, Furayyan, \& Alhemoud, 2009; Islam \& Ahmed, 2018). The above discussion concludes that transfer literature examines these variables separately with motivation towards transfer training. Thus, the present study aimed to investigate PSS and MTT through the mediating role of self-efficacy. Therefore, it was hypothesized that:

H1: PSS has positive impact on MTT.

H2: PSS has positive impact on self-efficacy.

H3: Self-efficacy mediates the positive association between PSS and MTT.

\section{Methods}

\subsection{Participants and Procedures}

The study considered employees of the banking sector. Despite the fact that employees of private and public organizations have varied level of MTT, still this study consider both the sectors in the light of the fact that in Pakistan this has turned into a challenge for both the sectors (Azam, 2016). Item response theory was used to select the sample of 480 (i.e. 24x20) and respondents were approached on convenience basis. Of these, 388 were used in the final analysis. First, permission was obtained from respective heads, and then respondents were assured about the anonymity of their responses. The data of this study was collected from January 2017 till December 2017.

On the basis of demographical characteristics, the majority of the respondents were male $(71.7 \%)$, less than 30 years of age $(59.1 \%)$, married $(46.8 \%)$, holding 18-years of education $(50.0 \%)$ with the current work experience of less than 5-years $(59.5 \%)$.

\subsection{Measures}

This study adapted scales from the previous studies and respondents were asked to respond on a fivepoint Likert scale ranging between "1-strongly disagree to 5-strongly agree".

PSS was measured using a four-item scale of Tsai and Tai (2003) with the sample item, "My supervisor encourages me to attend training program." POS was measured using a shortened six-item scale of Rhoades and Eisenberger (2002). This scale was noted as reliable, a sample item includes, "My 
organization really cares about my well-being." A ten-item scale of Schwarzer and Jerusalem, (1995) with the sample item, "I am confident that I could deal efficiently with unexpected events" was used for self-efficacy. Finally, MTT was measured through Machin and Forgarty's (2004) four-item scale with the sample item, "I intend to use the knowledge and skills acquired from training program when I get back on the job."

\section{Results}

\subsection{Primary analyses}

Initially, the primary analyses were conducted (including missing values, outliers, normality and multicollinearity). Since the data was collected through personal visit to banks and respondents were requested to fill all the questions, therefore, the data was found free from missing values. Regarding outliers, twelve questionnaires were considered redundant as they were having extreme values whereas, multicollinearity was examined using the correlation of values and all the variables were found to have correlation of less than 0.85 (see table 1).

Table 1: Descriptive statistics, reliability and correlation

\begin{tabular}{lllllllll}
\hline Variables & $\boldsymbol{\alpha}$ & $\mathbf{C R}$ & AVE & Mean & SD & $\mathbf{1}$ & $\mathbf{2}$ & $\mathbf{3}$ \\
\hline 1-POS & 0.82 & 0.65 & 0.58 & 3.83 & 0.72 & 1 & & \\
2-PSS & 0.78 & 0.61 & 0.56 & 3.61 & 0.69 & $0.49^{* *}$ & 1 & \\
3-Self-efficacy & 0.80 & 0.73 & 0.61 & 3.79 & 0.73 & $0.41^{* *}$ & $0.51^{* *}$ & 1 \\
4-MTT & 0.79 & 0.78 & 0.66 & 3.81 & 0.57 & $0.45^{* *}$ & $0.46^{* *}$ & $0.57^{* *}$ \\
\hline
\end{tabular}

"Note: POS = perceived organizational support, PSS = perceived supervisor support, MTT = motivation to transfer training, $\alpha=$ reliability, $\mathrm{CR}=$ composite reliability, $\mathrm{AVE}=$ average variance extracted, ** $\mathrm{P}<0.01$ ”

The values of descriptive statistics and correlation are presented in Table 1 . The values show that all the variables are reliable as the value of Cronbach Alpha is greater than the standard value of 0.70 (Hair, 2010). Moreover, the values of composite reliability and average variance extracted are also found to be well above the standard values of 0.60 and 0.50 respectively (Byrne, 2016). Further, POS is found to be positively relate to PSS $(r=0.49, P<0.01)$, self-efficacy $(r=0.41, P<0.01)$ and MTT $(r=0.45, P<0.01)$.

Confirmatory Factor Analysis (CFA):

First, CFA analysis were conducted because all the measures used in this study were adapted (Islam, Ahmed, Ali \& Ahmer, 2019). Initially, the values of model fit were not found to be good when compared with their standard values. Then modifications in error terms were made as per the suggestions of Hair et al., (2010) and the final model was found to be fit i.e. $x^{2} / d f=1.62$, CFI $=0.96$, SRMR $=0.03$, RMSEA $=0.05$ (see Table 2).

Table 2: Model fit values of CFA and structured model

\begin{tabular}{llll}
\hline Fit Index & CFA & $\begin{array}{l}\text { Hypothesized } \\
\text { Model }\end{array}$ & $\begin{array}{l}\text { Standardized } \\
\text { Values }\end{array}$ \\
\hline$" \chi^{2 "}$ & 581.47 & 579.25 & \\
"Degree of freedom $(d f) "$ & 376 & 359 & \\
"Normed $\chi^{2}\left(\chi^{2} / d f\right) "$ & 1.62 & 1.61 & $\leq 3$ \\
"Comparative fit index (CFI)" & 0.96 & 0.96 & $\geq 0.90$ \\
"Standard Root Mean Residual (SRMR)" & 0.03 & 0.02 & $<0.10$ \\
"Root Mean Square Error of Approximation (RMSEA)" & 0.05 & 0.04 & $<0.08$ \\
\hline
\end{tabular}

Sources of standardized values: Hair et al., (2010)

\subsection{Hypotheses Testing}

Subsequently, this study used structural equation modeling (SEM) to test the hypotheses and the values of model fit were found as $x^{2} / d f=1.61, \mathrm{CFI}=0.96, \mathrm{SRMR}=0.02, \mathrm{RMSEA}=0.04$ (see Table 2). The values identify that POS has positive effects on self-efficacy $(\beta=0.39, P<0.01)$ and MTT $(\beta=0.41, P$ 
$<0.01)$ which support suggested hypotheses H1 \& H2. Similarly, PSS was found to have positive effects on self-efficacy $(\beta=0.48, P<0.01)$ and MTT $(\beta=0.41, P<0.01)$, which support suggested hypotheses H4 \& H5 (see figure 1).

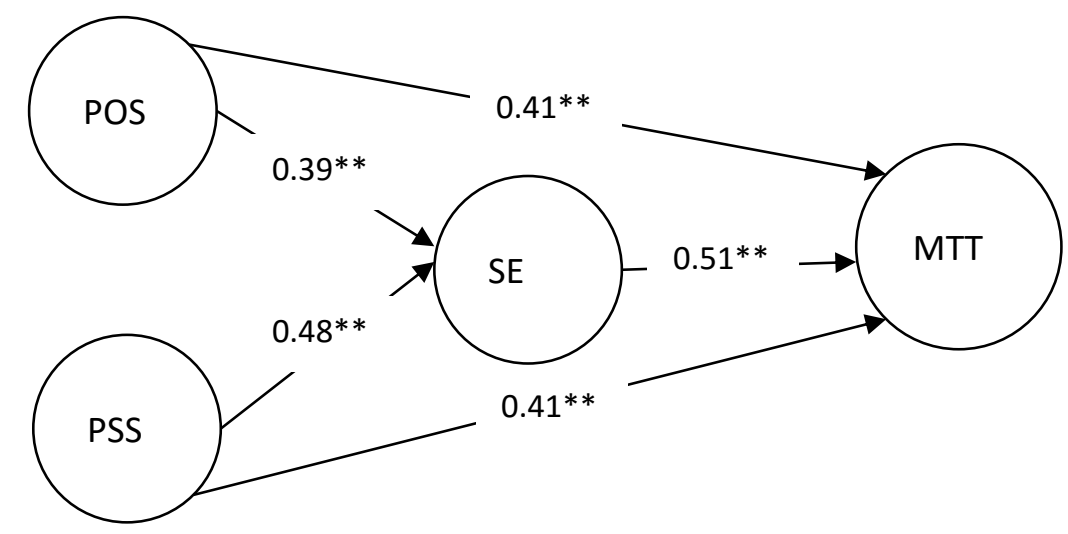

Figure 1: Structural Model

Further, path analysis was conducted to test the mediating effect of self-efficacy. Where direct paths between POS-MTT and PSS-MTT were compared with the indirect paths (i.e. path POS-SE $\times$ Path SEMTT) to examine its significance. The values depict that the indirect path between POS-MTT through self-efficacy $(\beta=0.20, P<0.01)$ was found to be lesser than direct path $(\beta=0.41, P<0.01)$, but still significant. This identifies partial mediating effect of self-efficacy between POS-MTT relationship and support hypothesis H3. Similarly, the indirect path between PSS-MTT through self-efficacy $(\beta=0.22, P$ $<0.01)$ was found to be lesser than direct path $(\beta=0.41, P<0.01)$, but significant and allowed to accept suggested hypothesis H6.

\section{Discussion and Implications}

This study aimed at fulfilling literary gaps regarding the mediating role of self-efficacy between the associations of PSS and POS with MTT. The results found POS as an important predictor of selfefficacy and MTT. These results are in line with Eisenberger et al's. (1986) organizational support theory as when employees feel of being cared by their organization, they not only found to be confident (i.e. self-efficacy) in achieving given tasks but also feel motivated to apply and transfer their learned skills through various programs (i.e. training programs here). Thus, employees perception of support from their organization contributed to building their confidence (Islam \& Ahmed, 2018), which further motivate them for transfer.

In addition, the study also found PSS to be positively contributing towards the development of employee's confidence and in turn, they were found to be motivated regarding the transfer of training. According to Gist and Mitchell (1992), being efficacious or not is dependent upon the level of support which employees perceive. Drawing from this notion and results of this study, it has confirmed that support from supervisor boosts employees' confidence on themselves, in turn, they get motivated to apply the same on others (by transferring their learned skills). In a similar study, Taylor. (2000) also noted that trainees having supportive supervisors are more likely to transfer their skilled at the workplace.

These results contribute to present literature in several ways. First, it extends the findings and scope of OST as previous studies have not examined the same on a frequent basis. Second, this study adds to the limited literature on transfer of training by identifying the mechanism between organizational and motivational training. Undoubtedly, training is important at all levels of an organization, but if it is not transferred by the trainees, it will remain unfruitful for the organization. Therefore, organizations are suggested to focus on motivating trainees to transfer their learned skills. This study suggests banking 
sector management to foster a cooperative environment where employees feel that they would be cared by them and they can communicate to their supervisors easily. Such an environment may be achieved by fostering learning environment (Islam \& Tariq, 2018). Learning environment gives enough confidence to the employees to share their ideas with each other especially with their immediate supervisors.

Though the study has implications, it is not free from limitations. First, the data for this study was collected from the banking sector considering the need of Pakistani banking sector. Therefore, to further generalize the results other sectors can be considered. Second, literature has suggested that cultures effect the employee's perception, it is therefore recommended to examine the same in other countries as well. Finally, as Pakistan is a male dominant country, most of the participants of this study were male, which may raise a question on gender biased results. Therefore, future researchers should consider both male and female respondents.

\section{References:}

Ahmed, I., Khairuzzaman Wan Ismail, W., Mohamad Amin, S., \& Islam, T. (2014). Role of perceived organizational support in teachers' responsiveness and students' outcomes: Evidence from a public sector University of Pakistan. International Journal of Educational Management, 28(2), 246-256.

Ahmed, I., \& Nawaz, M. M. (2015). Antecedents and outcomes of perceived organizational support: a literature survey approach. Journal of Management Development, 34(7), 867-880.

Al-Eisa, A. S., Furayyan, M. A., \& Alhemoud, A. M. (2009). An empirical examination of the effects of self-efficacy, supervisor support and motivation to learn on transfer intention. Management decision, 47(8), 1221-1244.

Awais Bhatti, M., Mohamed Battour, M., Pandiyan Kaliani Sundram, V., \& Aini Othman, A. (2013). Transfer of training: does it truly happen? An examination of support, instrumentality, retention and learner readiness on the transfer motivation and transfer of training. European Journal of Training and Development, 37(3), 273-297.

Azam. (2016). SBP Press Release.

Baldwin, T. T., \& Ford, J. K. (1988). Transfer of training: A review and directions for future research. Personnel psychology, 41(1), 63-105.

Bandura, A. (1995). Self-efficacy in changing societies: Cambridge university press.

Bates, R., \& Khasawneh, S. (2005). Organizational learning culture, learning transfer climate and perceived innovation in Jordanian organizations. International journal of training and development, 9(2), 96-109.

Bosset, I., \& Bourgeois, E. (2015). Motivation to transfer: linking perceived organizational support to training to personal goals. In Motivationsforschung im Weiterbildungskontext (pp. 169-199): Springer.

Bunch, K. J. (2007). Training failure as a consequence of organizational culture. Human resource development review, 6(2), 142-163.

Burke, L. A., \& Hutchins, H. M. (2007). Training transfer: An integrative literature review. Human resource development review, 6(3), 263-296.

Byrne, B. M. (2016). Structural equation modeling with AMOS: Basic concepts, applications, and programming: Routledge.

Caesens, G., \& Stinglhamber, F. (2014). The relationship between perceived organizational support and work engagement: The role of self-efficacy and its outcomes. Revue Européenne de Psychologie Appliquée/European Review of Applied Psychology, 64(5), 259-267.

Chauhan, R., Ghosh, P., Rai, A., \& Shukla, D. (2016). The impact of support at the workplace on transfer of training: a study of an Indian manufacturing unit. International journal of training and development, 20(3), 200-213.

Cheng, E. W., \& Hampson, I. (2008). Transfer of training: A review and new insights. International Journal of Management Reviews, 10(4), 327-341. 
Chiaburu, D. S., \& Lindsay, D. R. (2008). Can do or will do? The importance of self-efficacy and instrumentality for training transfer. Human Resource Development International, 11(2), 199206.

Chiaburu, D. S., \& Marinova, S. V. (2005). What predicts skill transfer? An exploratory study of goal orientation, training self-efficacy and organizational supports. International journal of training and development, 9(2), 110-123.

Cromwell, S. E., \& Kolb, J. A. (2004). An examination of work-environment support factors affecting transfer of supervisory skills training to the workplace. Human resource development quarterly, 15(4), 449-471.

Devos, C., Dumay, X., Bonami, M., Bates, R., \& Holton III, E. (2007). The Learning Transfer System Inventory (LTSI) translated into French: internal structure and predictive validity. International journal of training and development, 11(3), 181-199.

Eisenberger, R., Huntington, R., Hutchison, S., \& Sowa, D. (1986). Perceived organizational support. Journal of applied psychology, 71(3), 500.

Facteau, J. D., Dobbins, G. H., Russell, J. E., Ladd, R. T., \& Kudisch, J. D. (1995). The influence of general perceptions of the training environment on pretraining motivation and perceived training transfer. Journal of management, 21(1), 1-25.

Feiden, D. (2003). Bizarre postal bonding. New York Daily News.

Gegenfurtner, A., Festner, D., Gallenberger, W., Lehtinen, E., \& Gruber, H. (2009). Predicting autonomous and controlled motivation to transfer training. International journal of training and development, 13(2), 124-138.

Ghosh, P., Chauhan, R., \& Rai, A. (2015). Supervisor support in transfer of training: Looking back at past research. Industrial and Commercial Training, 47(4), 201-207.

Gist, M. E., \& Mitchell, T. R. (1992). Self-efficacy: A theoretical analysis of its determinants and malleability. Academy of Management review, 17(2), 183-211.

Gumuseli, A. I., \& Ergin, B. (2002). The manager's role in enhancing the transfer of training: A Turkish case study. International journal of training and development, 6(2), 80-97.

Hair, J. F., Black, W.C., Babin, B.J. and Anderson, R.E. . (2010). Multivariate Data Analysis (7th ed.): Prentice Hall, Upper Saddle River, NJ.

Islam, T. (2019). Motivation to transfer training in learning organization. Journal of management development, 38(4), 273-287.

Islam, T., \& Ahmed, I. (2018). Mechanism between perceived organizational support and transfer of training: Explanatory role of self-efficacy and job satisfaction. Management Research Review, 41(3), 296-313.

Islam, T., Ahmed, I., Ali, G., \& Ahmer, Z. (2019). Emerging trends of coffee cafes in Pakistan: Factors affecting revisit intention. British food Journal,121(9), 2132-2147.

Islam, T., Khan, M. M., Khawaja, F. N., \& Ahmad, Z. (2017). Nurses' reciprocation of perceived organizational support: the moderating role of psychological contract breach. International Journal of Human Rights in Healthcare, 10(2), 123-131.

Islam, T., \& Tariq, J. (2018). Learning organizational environment and extra-role behaviors: The mediating role of employee engagement. Journal of Management Development, 37(3), 258-270.

Islam, T., ur Rehman Khan, S., Norulkamar Ungku Bt. Ahmad, U., \& Ahmed, I. (2013). Organizational learning culture and leader-member exchange quality: The way to enhance organizational commitment and reduce turnover intentions. The Learning Organization, 20(4/5), 322-337.

Islam, T., Khan, M.M., Ahmed, I. and Mahmood, K. (2020). Promoting in-role and extra-role green behavior through ethical leadership: mediating role of green HRM and moderating role of individual green values. International Journal of Manpower, (In press). https://doi.org/10.1108/IJM-01-2020-0036

Islam, T., Ahmad, S., Kaleem, A. and Mahmood, K. (2021). Abusive supervision and knowledge sharing: moderating roles of Islamic work ethic and learning goal orientation. Management Decision, 59 (2), 205-222. 
Kontoghiorghes, C. (2002). Predicting motivation to learn and motivation to transfer learning back to the job in a service organization: A new systemic model for training effectiveness. Performance Improvement Quarterly, 15(3), 114-129.

Kupritz, V. W., \& Hillsman, T. (2011). The impact of the physical environment on supervisory communication skills transfer. The Journal of Business Communication (1973), 48(2), 148-185.

Lancaster, S., Di Milia, L., \& Cameron, R. (2013). Supervisor behaviours that facilitate training transfer. Journal of Workplace Learning, 25(1), 6-22.

Machin, M. A., \& Fogarty, G. J. (2004). Assessing the antecedents of transfer intentions in a training context. International journal of training and development, 8(3), 222-236.

Martin, H. J. (2010). Workplace climate and peer support as determinants of training transfer. Human resource development quarterly, 21(1), 87-104.

Nijman, D.-J. J., Nijhof, W. J., Wognum, A., \& Veldkamp, B. P. (2006). Exploring differential effects of supervisor support on transfer of training. Journal of European industrial training, 30(7), 529549.

Paulsen, H. F. K., \& Kauffeld, S. (2017). Linking positive affect and motivation to transfer within training: a multilevel study. International journal of training and development, 21(1), 35-52.

Pham, N. T., Segers, M. S., \& Gijselaers, W. H. (2013). Effects of work environment on transfer of training: empirical evidence from $\mathrm{M}$ aster of $\mathrm{B}$ usiness $\mathrm{A}$ dministration programs in $\mathrm{V}$ ietnam. International journal of training and development, 17(1), 1-19.

Rhoades, L., \& Eisenberger, R. (2002). Perceived organizational support: a review of the literature. Journal of applied psychology, 87(4), 698.

Richey, R. (1992). Designing Instruction for the Adult Learner: Systematic Training Theory and Practice: ERIC.

Riggle, R. J., Edmondson, D. R., \& Hansen, J. D. (2009). A meta-analysis of the relationship between perceived organizational support and job outcomes: 20 years of research. Journal of business research, 62(10), 1027-1030.

Rozkwitalska, M., \& Basinska, B. A. (2015). Job satisfaction in the multicultural environment of multinational corporations: Using the positive approach to empower organizational success. Baltic Journal of Management, 10(3), 366-387.

Saks, A. M., \& Belcourt, M. (2006). An investigation of training activities and transfer of training in organizations. Human Resource Management: Published in Cooperation with the School of Business Administration, The University of Michigan and in alliance with the Society of Human Resources Management, 45(4), 629-648.

Salas, E., \& Kosarzycki, M. P. (2003). Why don't organizations pay attention to (and use) findings from the science of training? Human resource development quarterly, 14(4), 487-491.

Schwarzer, R., \& Jerusalem, M. (1995). Optimistic self-beliefs as a resource factor in coping with stress. In Extreme stress and communities: Impact and intervention (pp. 159-177): Springer.

Silverman, R. E. (2012). So much training, so little to show for it. Wall Street Journal, 1-3.

Simosi, M. (2012). The moderating role of self-efficacy in the organizational culture-training transfer relationship. International journal of training and development, 16(2), 92-106.

Taylor, M. C. (2000). Transfer of learning in workplace literacy programs. Adult Basic Education, 10(1), 3-9.

Tsai, W.-C., \& Tai, W.-T. (2003). Perceived importance as a mediator of the relationship between training assignment and training motivation. Personnel review, 32(2), 151-163.

Van den Bossche, P., Segers, M., \& Jansen, N. (2010). Transfer of training: the role of feedback in supportive social networks. International journal of training and development, 14(2), 81-94.

Velada, R., Caetano, A., Michel, J. W., Lyons, B. D., \& Kavanagh, M. J. (2007). The effects of training design, individual characteristics and work environment on transfer of training. International journal of training and development, 11(4), 282-294.

Wei Tian, A., Cordery, J., \& Gamble, J. (2016). Returning the favor: positive employee responses to supervisor and peer support for training transfer. International journal of training and development, 20(1), 1-16. 
Yamkovenko, B., \& Holton, E. (2010). Toward a theoretical model of dispositional influences on transfer of learning: A test of a structural model. Human resource development quarterly, 21(4), 381-410.

Zumrah, A. R., \& Boyle, S. (2015). The effects of perceived organizational support and job satisfaction on transfer of training. Personnel review, 44(2), 236-254. 